\title{
Testes bioquímico (albumina e proteína de ligação da vitamina D) e molecular (gene KIT) para detecção de marcadores genéticos para pelagem tobiana em cavalos Pampa e Paint
}

\author{
[Biochemical (albumin and vitamin D-binding protein) and molecular (KIT gene) tests for detection of genetic \\ markers for Tobiano coat color in Pampa and Paint horses]
}

\author{
E.G.A. Coelho, D.A.A. Oliveira, C.S. Teixeira
}

Laboratório de Genética - Escola de Veterinária - UFMG

Av. Antônio Carlos, 6627

31270-010 - Belo Horizonte, MG

\begin{abstract}
RESUMO
Foram utilizados 159 cavalos Pampa, registrados na Associação Brasileira dos Criadores de Cavalo Pampa, e um grupo-controle, de 32 cavalos da raça Paint, ambos os grupos provenientes de plantéis de diferentes regiões brasileiras, com o objetivo de comparar os testes bioquímico e molecular para detecção de marcadores genéticos para pelagem tobiana em cavalos Pampa. Houve diferença significativa $(\mathrm{P}<0,001)$ entre os testes bioquímico e molecular, nos cavalos Pampa, mas o mesmo fato não ocorreu com os da raça Paint. Os resultados mostraram que o marcador molecular (KIT) foi mais eficiente na identificação dos prováveis cavalos homozigotos do que os marcadores bioquímicos albumina (Al) e proteína de ligação da vitamina $\mathrm{D}(\mathrm{Gc})$, em ambas as raças.
\end{abstract}

Palavras- chave: equino, albumina, proteína de ligação da vitamina D (Gc), gene KIT

\begin{abstract}
In this study, 159 Pampa horses, registered at the Associação Brasileira dos Criadores de Cavalo Pampa, and a control group of 32 Paint horses, both coming from herds located in different Brazilian regions, were used to compare biochemical and molecular tests for detection of genetic markers for the Tobiano coat color pattern in Pampa horses. Difference $(P<0.001)$ between biochemical and molecular tess in Pampa horses was observed, but not for the Paint horses. The results showed that the molecular marker (KIT) was more efficient to identify the probable homozygous dominant horses than the biochemical markers albumin (Al) and vitamin D-binding Protein $(G c)$, in both breeds.
\end{abstract}

Keywords: equine, albumin, vitamin D-biding protein $(G c)$, KIT gene

\section{INTRODUÇÃO}

Os melanócitos são células dendríticas e embriologicamente derivados de uma população germinativa de melanoblastos originários de ambos os lados da crista neural, pouco tempo após o fechamento do tubo neural. Na maioria das espécies, os melanoblastos começam o processo de melanização imediatamente antes ou logo depois de alcançarem seu destino (Sulaimon e Kitchell, 2003; Oliveira e Junior, 2003). Os melanoblastos migram do tronco da crista neural, seguindo um caminho dorsolateral entre o dermátomo dos somitos e o ectoderma, até seu destino na camada basal da epiderme ou no folículo piloso (Oliveira e Junior, 2003).

O receptor c-kit é um dos fatores relatados como participantes nos processos regulatórios para a manutenção do número e da atividade dos melanócitos na pele humana normal (Oliveira e Junior, 2003). O gene KIT codifica o receptor de membrana do tipo tirosinoquinase, receptor c-kit, para o fator de crescimento de célula germinativa

Recebido em 2 de setembro de 2009

Aceito em 10 de maio de 2010

E-mail: eduardogacoelho@yahoo.com.br 
(Stem Cell Growth Factor - SCF), também conhecido como fator de crescimento de mastócitos, KIT ligand ou steel factor, essencial na hematopoiese normal, nas melanogêneses e no desenvolvimento das células germinativas. Expressa-se no eritroide, no mieloide e nos progenitores de células hematopoiéticas multipotentes. Tem um papel-chave para o crescimento e a diferenciação dos melanócitos, das células hematopoiéticas e das células germinativas, e, além disso, é importante para migração dos melanócitos da crista neural para o tecido-alvo. Os melanoblastos expressam o gene KIT no período em que eles saem da crista neural (Johansson et al., 2005).

Mutações no gene KIT estão associadas aos problemas de pigmentação, anemia e/ou esterilidade e têm sido descritas mais comumente no homem, em camundongo e em porcos (Sulaimon e Kitchell, 2003; Johansson et al., 2005). Estudos mostram que a perda da expressão do gene KIT está associada à progressão do melanoma humano para o fenótipo metastático (Sulaimon e Kitchell, 2003).

Nos seres humanos, o gene KIT encontra-se no cromossomo 4. As mutações do proto-oncogene c-kit resultam em uma doença genética autossômica dominante da pigmentação, chamada piebaldismo. Trata-se de doença caracterizada por manchas congênitas da pele e poliose. O piebaldismo desenvolve características clínicas, tais como, manchas brancas na pele (leucoderma) e pelos brancos, diferentes do vitiligo com o qual é frequentemente confundido. As manchas despigmentadas estão presentes ao nascimento e são geralmente estáticas na sua forma e distribuição. Têm sido mencionadas desde a Grécia antiga e foram uma das primeiras manifestações de doenças genéticas autossômicas dominantes reconhecidas (Oliveira e Junior, 2003). Em porcos, o gene KIT corresponde ao loco dominante White (I) no cromossomo 8. Sete alelos diferentes, com efeitos fenotípicos diversos, têm sido descritos, tais como: o alelo recessivo tipo selvagem i, o alelo patch $\mathrm{I}^{\mathrm{P}}$, resultando em um fenótipo com manchas brancas mais ou menos extensas, o alelo Belt $\mathrm{I}^{\mathrm{Be}}$, cujo fenótipo representa uma mancha branca que se estende das patas dianteiras e cruza o dorso dianteiro, os alelos dominantes White $\mathrm{I}^{1}, \mathrm{I}^{2}, \mathrm{I}^{3}$ e o alelo $\mathrm{I}^{\mathrm{L}}$ (Giuffra et al., 1999; Johansson et al., 2005). O gene KIT foi mapeado em cavalos no cromossomo 3q21 (Lear et al., 1998) ligado aos marcadores bioquímicos (Al, Gc e Es) e também aos marcadores microssatélites LEX57, UCDEQ437, LEX007 e ASB23 (Lindgren et al., 1998). Os genes que codificam as pelagens rosilha e tobiana também estão proximamente ligados nessa região, indicando que aquela onde se situam é homóloga às do cromossomo 4 humano (HSA4), cromossomo 5 dos camundongos (MMU5) e cromossomo 8 dos porcos (SSC8) (Marklund et al., 1999).

Como as mutações no loco KIT são responsáveis por padrões de manchas de coloração branca em humanos, porcos e ratos, acredita-se que tais mutações poderiam ser responsáveis por alguns padrões de manchas brancas nos cavalos. Em estudo realizado por Terry et al. (2001), foi avaliada a relação do gene KIT com a pelagem apalusa, revelando que tal gene não é responsável por esse padrão. Brooks e Bailey (2005) mostraram que o gene KIT está relacionado ao padrão de pelagem sabino, caracterizado por manchas brancas na face e nas orelhas, nas extremidades das patas e no ventre e por interpolação de pelos brancos na porção mediana semelhante à interpolação que acontece na pelagem rosilha. Tal padrão de pelagem é muito confundido com outros com manchas brancas, principalmente tobiano, e é considerado um tipo de pelagem overo (Sponenberg, 1996; Brooks e Bailey, 2005).

O padrão de pelagem tobiano é causado pelo alelo tobiano (To), possui o padrão de herança mendeliana simples, herdado como um gene dominante. Em várias raças de cavalos, o loco tobiano (To) é ligado a locos que codificam as proteínas sanguíneas albumina $(\mathrm{Al})$ e proteína de ligação da vitamina D (Gc) (Bowling, 1987; Sponenberg, 1996). O cromossomo contendo o alelo para tobiano usualmente possui um haplótipo com os alelos $\mathrm{Al}^{\mathrm{B}}$ e $\mathrm{Gc}^{\mathrm{S}}$. Essa ligação faz parte do grupo de ligação II (LGII) dos equinos e pode ser usada para identificar os prováveis indivíduos homozigotos para o gene To, cujo genótipo será $\mathrm{Al}^{\mathrm{BB}}, \mathrm{Gc}^{\mathrm{SS}}$, ToTo. No entanto, exceções a essa fase de ligação vêm sendo demonstradas em algumas raças (Duffield e Goldie, 1998). 
Pesquisa feita por Marklund et al. (1999) fortaleceu a hipótese de que o gene KIT é o responsável pelo padrão rosilho nos cavalos. Como os genes que codificam a pelagem rosilha, $\mathrm{Al}$ e $\mathrm{Gc}$, fazem parte do LGII dos equinos, e o gene que codifica o padrão tobiano, também, logo o gene KIT é um gene candidato a codificar o padrão tobiano. Brooks et al. (2002) revelaram que há uma região do DNA homólogo equino do proto-oncogene c-kit (KIT) fortemente associada ao gene tobiano. Neste estudo, foi identificado um polimorfismo da enzima de restrição MSP1 no íntron 13 do cromossomo 3 (3q21-q22.1) dos equinos pela comparação da sequência de DNA de cavalos com pelagem sólida e cavalos homozigotos para o gene tobiano. $\mathrm{O}$ alelo associado à pelagem sólida foi designado KM0, sendo o indivíduo KM0/KM0 aquele que não possui o sítio de restrição da enzima, enquanto o alelo associado ao padrão tobiano criou um fragmento adicional reconhecido pela enzima de restrição, o qual foi designado KM1, sendo o cavalo heterozigoto aquele que possui o genótipo KM1/KM0, e o cavalo KM1/KM1 o provável homozigoto, uma vez que esse gene é um marcador genético indireto para a pelagem tobiana. Foi demonstrado, neste estudo, que todos os 129 tobianos possuíam o alelo KM1. Contudo, três dos 104 sólidos também possuíam o alelo KM1. Desse modo, mostrou-se que, embora o alelo KM1 esteja fortemente associado ao gene para To, a associação não é perfeita. Porém, esse teste tem sido mais eficiente para identificar cavalos prováveis homozigotos tobianos do que os testes bioquímicos. Foi constatado que, quando ocorrem eventos, como desequilíbrio de ligação entre os locos tobiano e albumina (Duffield e Goldie, 1998), os quais causam associações diferentes entre os locos (Al, Gc e To) e interferem na identificação dos prováveis homozigotos, tais eventos não afetam o loco KIT.

Testes prévios, que utilizaram marcadores bioquímicos (Al e Gc) em alguns cavalos registrados na Associação Brasileira de Criadores de Cavalos Pampa (ABCPAMPA) que possuíam todas as progênies com padrão de pelagem tobiano - indicador de homozigose para o loco que codifica tal padrão de pelagem -, foram ineficientes na detecção dos indivíduos homozigotos (Coelho et al., 2007).
Diante desses resultados, o presente trabalho teve como objetivo avaliar o marcador molecular KIT (marcador para o gene KIT) para identificar os indivíduos homozigotos dominantes, uma vez que todas as suas progênies expressarão o padrão de pelagem tobiana, e comparar a eficiência entre os marcadores bioquímicos e molecular na identificação de tais indivíduos nas raças Pampa e Paint Brasileiro.

\section{MATERIAL E MÉTODOS}

Foram colhidas amostras de soro sanguíneo de 159 cavalos Pampa machos e fêmeas e suas progênies, registrados pela ABCPAMPA, provenientes de vários plantéis, de diferentes regiões brasileiras. Também foi testado um grupo-controle, composto por 32 cavalos da raça Paint, usados na rotina do Laboratório de Genética da Escola de Veterinária da UFMG.

As amostras de soro foram colhidas em tubos a vácuo, sem anticoagulante, estéreis, a um volume de $5 \mathrm{~mL}$, e armazenadas sob refrigeração a $4{ }^{\circ} \mathrm{C}$. Posteriormente, o material foi centrifugado a 4.400RPM, para separação do soro, e, então, divido em alíquotas e armazenado em freezer a $20^{\circ} \mathrm{C}$. As amostras foram submetidas à eletroforese em gel de amido e à eletroforese em gel de poliacrilamida (PAGE) para separação e identificação dos alelos presentes nas proteínas $\mathrm{Al}$ e Gc. Na preparação dos géis de amido para a $\mathrm{Al}$, foi utilizado o método desenvolvido por Scott (1970), modificado. Para o gel de PAGE, a técnica empregada foi a de Juneja et al. (1978), modificada.

Foram colhidas amostras de pelos com bulbos dos 159 cavalos Pampa e dos cavalos Paint. O protocolo usado para a extração de DNA foi fornecido pelo Laboratório de Genética Veterinária da Universidade da Califórnia-Davis (uso sob licença).

Para o estudo do loco que codifica a pelagem tobiana, foram feitas amplificações pela PCR com primer específico e digestão com a enzima de restrição MSP1. O desenho do primer (KM) usado para se fazer a amplificação pela PCR bem como o protocolo de amplificação e corte com a enzima de restrição MSP1 foram gentilmente cedidos pelo Dr. E. Gus Cothran do Equine Parentage Testing and Research Laboratory Veterinary Science Departament, College of 
Agriculture - University of Kentucky, Lexington, $K Y$-USA (uso sob licença). O produto da digestão da enzima de restrição MSP1 foi separado por eletroforese em gel de PAGE $8 \%$ a $100 \mathrm{~V}$ por quatro horas e corado pelo método do nitrato de prata. Após a coloração, o gel foi analisado em trasiluminador de luz branca e fotografado em câmera digital (Sony Digital Mavica - MVCFD5).

Foi feito estudo de dispersão de frequência entre os testes bioquímico e molecular, utilizando-se o teste qui-quadrado $\left(\chi^{2}\right)$ e nível de $5 \%$ de significância. Para essa análise, foram usadas as amostras que apresentaram resultado tanto para os marcadores bioquímicos ( $\mathrm{Al}$ e $\mathrm{Gc}$ ), quanto para o marcador molecular (KIT).

\section{RESULTADOS E DISCUSSÃO}

Para o marcador bioquímico albumina, foram detectados dois alelos, A e B, e identificados animais com três genótipos, AA, AB e BB. O marcador bioquímico Gc apresentou também três genótipos, FF, FS e SS.

O marcador molecular KIT apresentou um alelo com o sítio de restrição para a enzima MSP1, designado KM1, bem como um alelo sem o sítio de restrição da enzima MSP1, designado KM0, segundo Brooks et al. (2002). Assim sendo, foram observados: 1. Fragmento de 700pb e genótipo homozigoto KM0/KM0 - fragmento não digerido pela enzima MSP1; 2. Fragmentos de $325 \mathrm{pb}$ e $425 \mathrm{pb}$ e genótipo tobiano homozigoto KM1/KM1; 3. Fragmentos de $325 \mathrm{pb}, 425 \mathrm{pb}$ e $700 \mathrm{pb}$ e genótipo tobiano heterozigoto KM1/KM0.

Os genótipos KM1/KM1, KM1/KM0 e KM0/KM0 são demonstrados na Fig.1.

$\mathrm{Na}$ Tab.1, são apresentados os resultados comparativos entre os testes bioquímico albumina, alelos A e B, e Gc, alelos F e S, e molecular - KIT, alelos KM0, KM1 para os cavalos Pampa.

Houve diferença significativa $(\mathrm{P}<0,001)$ entre os testes, indicando que o teste molecular foi capaz de diagnosticar os prováveis indivíduos homozigotos dominantes para o loco tobiano no cavalo Pampa. Já o teste bioquímico foi ineficaz, não sendo indicado na identificação dos prováveis homozigotos (BBSS) nessa raça. Os resultados bioquímicos indicariam a quebra de ligação gênica entre os locos Alb, Gc e tobiano, semelhante ao achado de Duffield e Goldie (1998), que encontraram diferente fase de ligação $\mathrm{Al}^{\mathrm{A}}$ To, podendo ser usado para representar uma recombinação histórica entre os locos tobiano e albumina de um ancestral comum. Por outro lado, há também a possibilidade de que as fases $\mathrm{Al}^{\mathrm{A}}$ e $\mathrm{Al}^{\mathrm{B}}$ com To tenham sido originadas como mutações independentes dos genes tobiano e albumina.

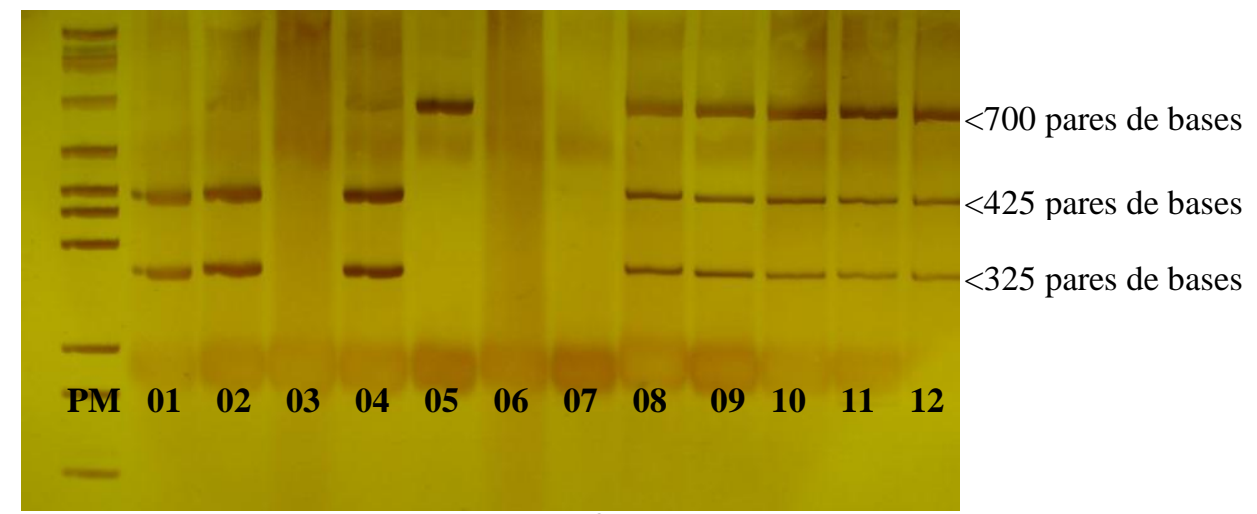

PM - Padrão de peso molecular - pGEM ${ }^{\circledR}$ DNA Markers - Promega.

canaletas - 01, 02, 04 - homozigotos KM1/KM1;

canaleta - 05 - sem corte com a enzima MSP1, KM0/KM0;

canaletas - 03, 06, 07 - amostras não amplificadas

canaletas - 08, 09, 10, 11, 12 - heterozigotos KM1/KM0.

Figura 1. Gel de poliacrilamida $8 \%$ corado com nitrato de prata - primer KM, em cavalos da raça Pampa. 
Tabela1. Resultados dos testes bioquímico e molecular para pelagem tobiana em cavalos Pampa

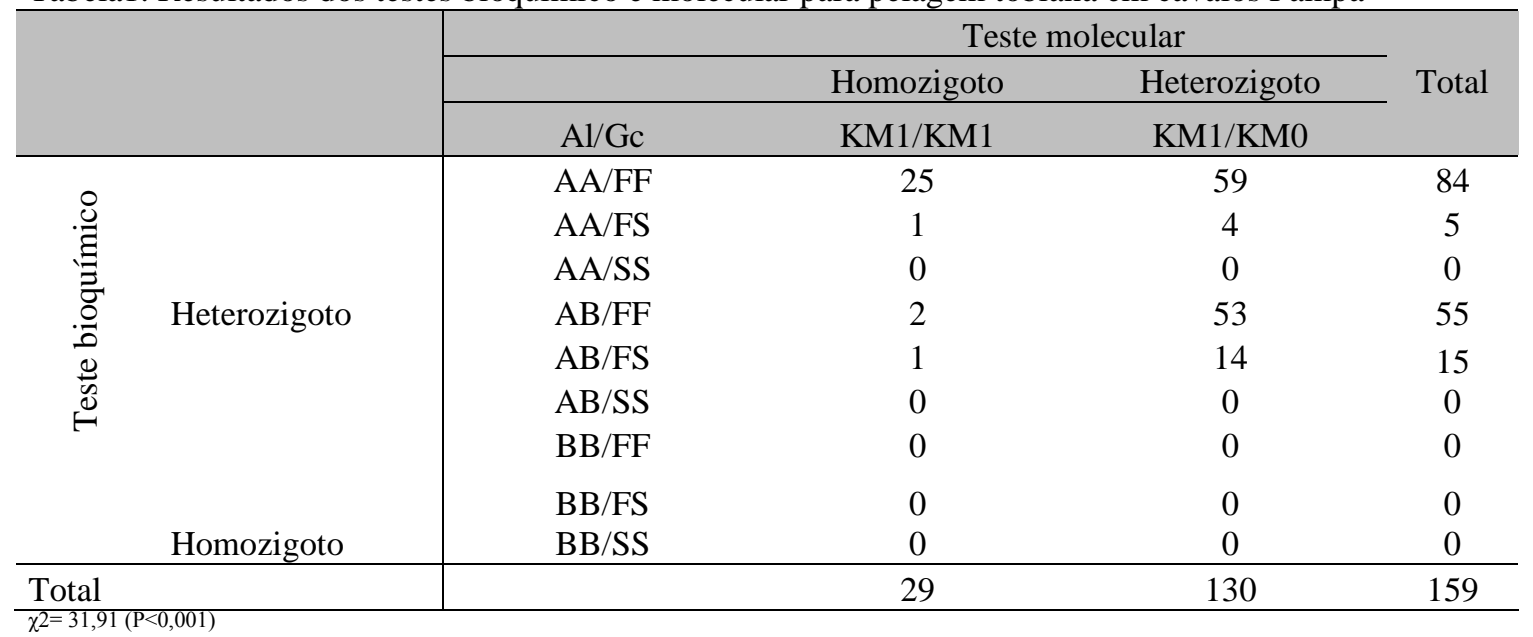

Segundo Nicholas (1999), a ligação gênica entre dois locos decresce numa proporção (1-c) por geração, em que c é a fração de recombinação entre os locos. Com base nos resultados obtidos, supõe-se que, ao longo do processo de formação das raças que constituem a base do cavalo Pampa, o desequilíbrio de ligação entre os locos Al, Gc e To pode ter desaparecido, ou seja, a ligação genética entre eles pode ter sigo desfeita. Isso explicaria a ineficácia do teste das proteínas $\mathrm{Al}$ e Gc como marcadores genéticos para a pelagem tobiana no cavalo Pampa. Tal situação é distinta no cavalo Paint, cuja "raça" foi formada basicamente por animais Quarto de Milha, que apresentavam pelagem malhada, não aceitos para registro pela American Quarter Horse Association

(http://www.portalpainthorse.com.br/index.php? page $=$ conheca_ph).

$\mathrm{Na}$ Tab. 2, são apresentados os resultados comparativos entre os testes bioquímico e molecular para os cavalos Paint.

Tabela 2. Resultados dos testes bioquímico e molecular para pelagem tobiana em cavalos da raça Paint

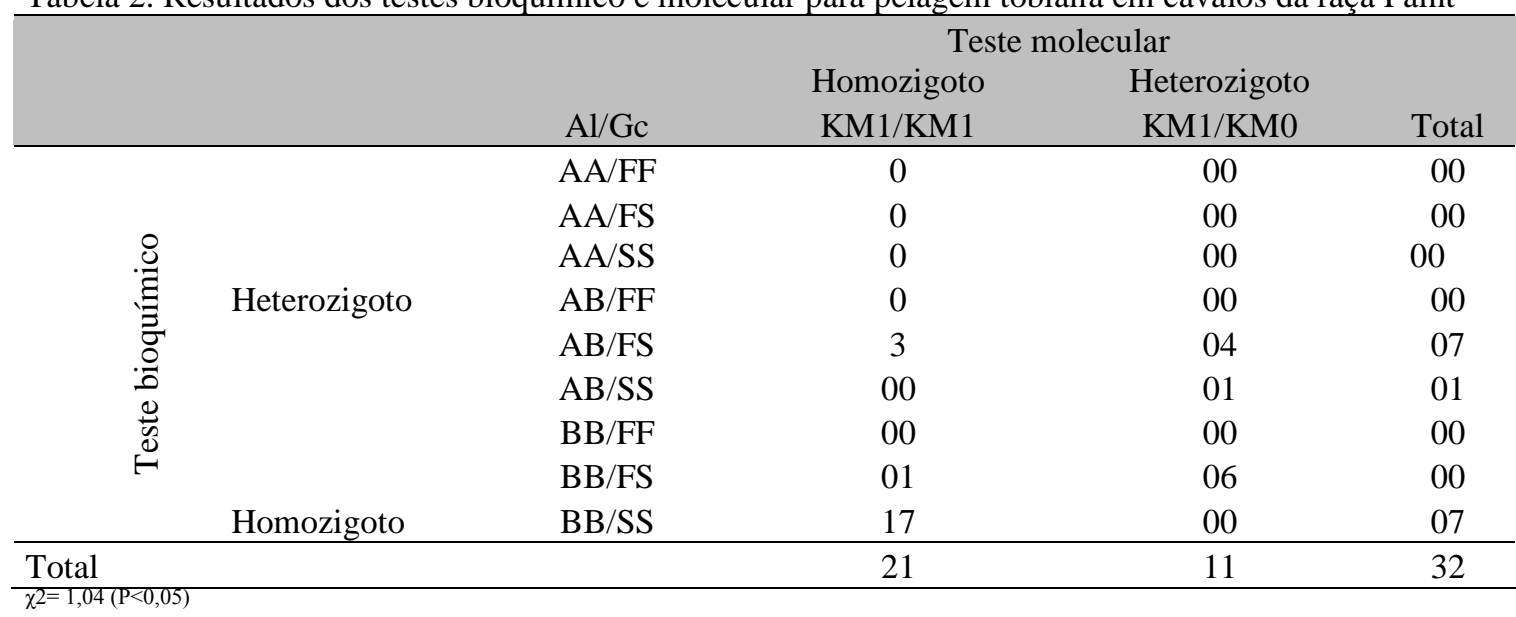

Os resultados mostraram que para o cavalo Paint não há diferença significativa entre os testes de marcadores bioquímico e molecular, pois ambos foram eficientes na identificação dos indivíduos homozigotos dominantes para o loco tobiano.
Segundo Brooks et al. (2002), quando ocorrem eventos que causam associações diferentes dos locos Al, Gc e To, tais eventos não afetam o alelo KM1, nem quebram a ligação com o marcador KIT, o que pode ocorrer com os 
marcadores bioquímicos (Al e Gc). Sendo assim, o teste molecular é mais recomendável na identificação dos tobianos homozigotos.

\section{CONCLUSÕES}

$\mathrm{O}$ teste do marcador molecular (KIT) foi eficiente na identificação dos indivíduos prováveis homozigotos, tanto em cavalos Pampa quanto em cavalos Paint Brasileiro. Os marcadores bioquímicos albumina e proteína de ligação da vitamina D não foram eficientes na detecção dos prováveis homozigotos dominantes nos cavalos Pampa.

\section{REFERÊNCIA BIBLIOGRÁFICAS}

BOWLING, A.T. Equine linkage group II: phase conservation of To with $\mathrm{Al}^{\mathrm{B}}$ and $\mathrm{Gc}^{\mathrm{S}}$. J. Hered., v.78, p.248-250, 1987.

BROOKS, S.A.; TERRY, R.B.; BAILEY, E. A PCR-RFLP for KIT associated with tobiano spotting pattern in horses. Anim. Genet., v.33, p.301-303, 2002.

BROOKS, S.A.; BAILEY, E. Exon skipping in the KIT gene causes a Sabino spotting pattern in horses. Mamm. Genome, v.16, p.893-902, 2005.

COELHO, E.G.A., OLIVEIRA, D.A.A., COTHRAN, E.G., et al. Teste de marcadores bioquímicos na identificação de prováveis indivíduos homozigotos dominantes para o gene tobiano em cavalos Pampa. Arq. Bras. Med. Vet. Zootec., v.59, p.991-998, 2007.

DUFFIELD D.A.; GOLDIE, P.L. Tobiano Spotting Pattern in Horses: Linkage of To with $\mathrm{Al}^{\mathrm{A}}$ and Linkage Disequilibrium. J. Hered., v.89, p.104-106, 1998.

GIUFFRA, E.; EVANS, G.; TÖRNSTEN, A. et al. The Belt mutation in pigs is an allele at the Dominant white (I/KIT) locus. Mamm. Genome, v.10, p.1132-1136, 1999.

JOHANSSON, A.; PIELBERG, G.; ANDERSSON, L. et al. Polymorphism at the porcine Dominant white/KIT locus influence coat color and peripheral blood cell measures. Anim. Genet., v.36, p.288-296, 2005.
JUNEJA, R.K.; GAHNE, B.; SANDBERG, K. Genetic polymorphism of the vitamin D binding protein and another post-albumin protein in horse serum. Anim. Blood Groups Biochem. Genet., v.9, p.29-36, 1978.

LEAR, T.L.; COOGLE, L.D.; BAILEY, E. Assignment of the horse mitochrondrial glutamate oxaloacetate transaminase 2 (GOT2) and c-kit Hardy-Zuckerman 4 feline sarcoma viral oncogene homology (KIT) to horse chromosome 3 by in situ hybridization. Cytog. Cell Genet., v.82, p.112-113, 1998.

LINDGREN, G.; SANDBERG, K; PERSSON, $\mathrm{H}$. et al. A primary male autosomal linkage map of the horse genome. Genome Res., v.8, p.951966, 1998.

MARKLUND, S.; MOLLER, M.; SANDBERG, $K$. et al. Close association between sequence polymorphism in the KIT gene and roan coat color in horses. Mamm. Genome, v.10, p.283288, 1999.

NICHOLAS, F.W. Controle genético e ambiental das doenças hereditárias. In: Introdução à genética veterinária. Porto Alegre: Artes Médicas Sul Ltda, 1999. 326p.

OLIVEIRA, I.O.; JUNIOR, H.L.A. Conhecimentos atuais sobre a biologia dos melanócitos no folículo piloso humano. An. Bras. Dermatol., v.78, p.331-343, 2003.

SCOTT, A.M. A single acid gel for the separation of albumin and transferrins in horse. Anim. Blood Groups Biochem. Genet., v.1, p.253-254, 1970.

SPONENBERG, D.P. Patterns of white. In.: Equine color genetics. Iowa: Iowa State University, 1996. cap.4, p.53-80.

SULAIMON, S.S.; KITCHELL, B.E. The biology of melanocytes. Vet. Dermatol., v.14, p.57-65, 2003.

TERRY, R.R.; BAILEY, E.; BERNOCO, D. et al. Linked markers exclude KIT as the gene responsible for appaloosa coat color spotting patterns in horses. Anim. Genet., v.32, p.98-101, 2001. 